\title{
Placental Transfusion in Preterm Neonates
}

\author{
Deepak Chawla ${ }^{1}$ (D)
}

Received: 19 December 2017 / Accepted: 26 December 2017 / Published online: 17 February 2018

(C) Dr. K C Chaudhuri Foundation 2018

Preterm neonates are at higher risk of various short-tem and long-term morbidities. Transition from fetal to postnatal period, is the one of the most critical period in preterm neonates, majority of who need support to make a successful transition. Placental transfusion is one intervention, which has been proposed to have both short- and long-term benefits. A systematic review including fifteen studies (738 neonates) showed that in preterm neonates, placental transfusion was associated with better hemodynamic stability at birth, decreased need of inotropic support, lower need of blood transfusions and lower risks of intraventricular hemorrhage, necrotizing enterocolitis and sepsis [1] However, a recently published large randomized controlled trial failed to show any short-term benefit with placental transfusion in extremely preterm neonates [2]. Despite lack of decrease in short-term morbidities or death before hospital discharge, delaying cord clamping or milking of cord before clamping leads to transfer of more blood to infant, carrying with it extra iron, growth factors and stem cells.

Iron is needed not only for intracellular energy metabolism but also for DNA replication, neurotransmitter synthesis and myelination [3]. Rapidly dividing cells need higher supply of iron due to latter's role in DNA replication. Preterm neonates have lower stores of iron due to interruption in accretion of iron during third trimester. Anemia during pregnancy further limits the transfer of iron to fetus. Infants born in low- and middleincome countries (LMIC) with high incidence of anemia among pregnant women and poor weaning practices later in infancy stand to have greatest benefit from placental transfusion. A large number of studies conducted among term neonates in LMIC have shown that delay in cord clamping at birth for $1-3 \mathrm{~min}$ is associated with improved iron stores and lower incidence of anemia later in infancy [4]. Similar long-term studies are lacking in preterm neonates. In this issue of the journal, Das B and

Deepak Chawla

drdeepakchawla@gmail.com

1 Department of Pediatrics, Government Medical College Hospital, Chandigarh, India colleagues report that preterm neonates born at 30-33 wk of gestation have improved iron stores at discharge after delayed cord clamping for $1 \mathrm{~min}$ or cord milking in comparison to cord clamping within $10 \mathrm{~s}$ [5]. Investigators need to be congratulated for conducting this logistically difficult study which needed to surmount challenges of enrolment and random allocation before birth, being prepared to administer the allocated intervention at birth and conflict with initiation of resuscitation. Although the study does not demonstrate persistence of improved iron stores at 3 mo of postmenstrual age, this may be because of small number of neonates who contributed to information at this time-point. Larger studies with long-term outcome and better follow-up rates are needed. It would also be interesting to investigate if improved iron stores in preterm neonates are associated with better neurophysiological structure (e.g., myelination in MRI) and function (improved inter-peak latency in brainstem evoked potential or better amplitude in visual evoked potential) and improved cognitive function later in childhood.

\section{Compliance with Ethical Standards}

Conflict of Interest None.

\section{References}

1. Rabe H, Diaz-Rossello JL, Duley L, Dowswell T. Effect of timing of umbilical cord clamping and other strategies to influence placental transfusion at preterm birth on maternal and infant outcomes. Cochrane Database Syst Rev. 2012;8:CD003248.

2. Tarnow-Mordi W, Morris J, Kirby A, et al. Delayed versus immediate cord clamping in preterm infants. N Engl J Med. 2017;377:244555. https://doi.org/10.1056/NEJMoa1711281.

3. deRegnier R-AO, Georgieff MK. Fetal and neonatal iron metabolism. In: Polin RA, Fox WW, Abman SH, editors. Fetal Neonatal Physiol, 4th ed. Philadelphia: Elsevier; 2011. p. 374-83.

4. McDonald SJ, Middleton P, Dowswell T, Morris PS. Effect of timing of umbilical cord clamping of term infants on maternal and neonatal outcomes. Cochrane Database Syst Rev. 2013;7:CD004074.

5. Das B, Sundaram V, Kumar P, Mordi WT, Dhaliwal LK, Das R. Effect of placental transfusion on iron stores in moderately preterm neonates of 30-33 weeks gestation. Indian J Pediatr. 2017; https://doi.org/10.1007/s12098-017-2490-2. 